\title{
The risk of cardiovascular disease following breast cancer by Framingham risk score
}

\author{
Sofie A. M. Gernaat ${ }^{1,9}$. Jolanda M. A. Boer ${ }^{2}$. Desiree H. J. van den Bongard ${ }^{3}$. Angela H. E. M. Maas ${ }^{4}$. \\ Carmen C. van der Pol ${ }^{5} \cdot$ Rhodé M. Bijlsma $^{6}$ • Diederick E. Grobbee ${ }^{1} \cdot$ Helena M. Verkooijen $^{7} \cdot$ Petra H. Peeters ${ }^{1,8}$
}

Received: 15 February 2018 / Accepted: 16 February 2018 / Published online: 28 February 2018

(c) The Author(s) 2018. This article is an open access publication

\begin{abstract}
Objectives This study evaluates the risk of cardiovascular disease (CVD) following breast cancer, accounting for baseline CVD risk.

Methods Within the EPIC-NL (Dutch part of the European Prospective Investigation into Nutrition and Cancer) cohort, 1103 women were diagnosed with breast cancer. For every breast cancer patient, 3-4 women without breast cancer $(n=4328)$ were selected matched for age, year, and time since cohort enrollment. Based on CVD risk factors at cohort enrollment, 10-year risk of CVD was calculated and categorized: low $(<10 \%)$, intermediate (10-20\%), high $(>20 \%)$. Cox proportional hazard models assessed the risk of CVD events (hospitalization or mortality) and CVD mortality of women with versus without breast cancer, adjusted for baseline CVD risk.

Results After median follow-up of 5 and 6 years, 92 (8.3\%) and 325 (7.5\%) CVD events occurred in women with and without breast cancer, respectively. In the low CVD risk group, women with breast cancer had 1.44 (95\% CI 1.00-2.06) times higher risk of CVD events than women without breast cancer. In the intermediate and high CVD risk categories, risk of CVD events was similar in women with and without breast cancer. Overall, women with breast cancer had 1.77 (95\% CI 1.10-2.86) times higher risk of CVD mortality than women without breast cancer.

Conclusions Among women with low CVD risk, women with breast cancer have a higher risk of CVD event than women without breast cancer. Overall, women with breast cancer have a higher risk of CVD mortality than women without breast cancer.
\end{abstract}

Keywords Breast cancer $\cdot$ Cardiovascular disease $\cdot$ Mortality $\cdot$ Morbidity $\cdot$ Risk

Electronic supplementary material The online version of this article (https://doi.org/10.1007/s10549-018-4723-0) contains supplementary material, which is available to authorized users.

Helena M. Verkooijen

h.m.verkooijen@umcutrecht.nl

Sofie A. M. Gernaat

sofie.gernaat@gmail.com

1 Department of Epidemiology, Julius Center for Health Sciences and Primary Care, University Medical Center Utrecht, Utrecht University, Utrecht, The Netherlands

2 Centre for Nutrition, Prevention and Health Services, National Institute for Public Health and the Environment (RIVM), Utrecht University, Bilthoven, Utrecht, The Netherlands

3 Department of Radiation Oncology, University Medical Center Utrecht, Utrecht University, Utrecht, The Netherlands
4 Department of Cardiology, Radboud University Medical Center Nijmegen, Nijmegen, The Netherlands

5 Department of Surgical Oncology, Utrecht University, Utrecht, The Netherlands

6 Department of Medical Oncology, University Medical Center Utrecht, Utrecht University, Utrecht, The Netherlands

7 Imaging Division, University Medical Center Utrecht, Utrecht University, Utrecht, The Netherlands

8 Department of Epidemiology and Biostatistics, School of Public Health, Imperial College, London, UK

9 Present Address: Utrecht, The Netherlands 


\section{Introduction}

Breast cancer incidence and survival are high in developed countries [1]. Survival has substantially improved due to early detection by screening programs and improved treatments [2-4]. This has resulted in over 3 million 5-year breast cancer survivors worldwide [1]. Many of these women will die of conditions other than breast cancer [5, 6]. Cardiovascular disease (CVD) is an important cause of death in the general population, also following breast cancer with $24 \%$ of patients over 65 years die of this disease $[7,8]$.

Breast cancer patients may have a higher CVD risk compared to the general population. Although cancer treatments such as anthracycline-based regimens, trastuzumab, and radiotherapy reduce the risk of cancer recurrence and death, they have been associated with an increased risk of CVD [9-16]. Anthracycline-based chemotherapy and trastuzumab increase the risk of heart failure by fivefold compared to regimens without these components [17, 18]. Furthermore, radiotherapy increases the risk of death from circulatory disease with 25\% [11]. Another reason that breast cancer patients may have a higher CVD risk is because risk factors for both diseases overlap, especially risk factors as obesity and physical inactivity [19]. Breast cancer patients may have a higher prevalence of CVD risk factors than the general population. Pre-existing CVD risk factors have also been associated with a higher risk of cancer treatment-induced cardiotoxicity [20,21].

Except for a few studies [7, 22, 23], the majority did not adjust for traditional CVD risk factors when investigating the risk of CVD following breast cancer. The Framingham risk score is a composite score based on traditional CVD risk factors (age, sex, current smoking, diabetes, and high systolic blood pressure) to predict the absolute 10 -year baseline CVD risk [24]. The current study assessed the risk of CVD for women with breast cancer, compared to women without breast cancer, with a low $(<10 \%)$, intermediate $(10-20 \%)$, and high $(>20 \%)$ baseline risk of CVD. Next, we assessed the risk of death from CVD adjusted for the baseline CVD risk.

\section{Methods and materials}

\section{Study design and population}

The current study included women participating in the Dutch contribution to the European Prospective Investigation into Cancer and Nutrition (EPIC-NL), which consists of the MORGEN and Prospect cohorts [25]. Details on the design and rationale of the EPIC-NL study have been described elsewhere [26]. Briefly, prospect is a prospective cohort study that was set up to investigate the role of nutrition and biomarkers in the etiology of cancer. The MORGEN cohort was set up to monitor risk factors for chronic diseases in the Netherlands. MORGEN includes 22,654 men (45\%) and women aged 20-64 years residing in three Dutch towns (Amsterdam, Doetinchem, and Maastricht) between 1993 and 1997 [27]. Prospect includes 17,357 women aged 49-70 living in the city of Utrecht or its vicinity who participated in the nationwide Dutch breast cancer screening program between 1993 and 1997 [28]. The ethics committees of the respective institutions approved both studies, and all participants gave their written informed consent.

Women with prevalent cancer at EPIC-NL enrolment (t0) were not eligible for the current study. Furthermore, women were not included if they had not given consent for linkage with vital status or morbidity registries $(n=2717)$ or had missing information on hospital admission or cause of death $(n=55)$. The current study included all women diagnosed with a first in situ or invasive breast cancer during follow-up in the EPIC-NL cohort until December 31, 2010 (referred to as 'exposed' in the current study). Subsequently four women without breast cancer during follow-up were matched to the exposed women on age at breast cancer diagnosis $(t 1)$, year of breast cancer diagnosis $(t 1)$, and time between EPIC-NL enrolment $(t 0)$ and breast cancer diagnosis $(t 1)$ (the "unexposed' group). We would like to stress that this is not a matched case-control study, but rather a prospective followup study, matched on the exposure status (breast cancer).

The final study population consisted of 1103 women diagnosed with breast cancer and 4328 women without breast cancer.

\section{Exposure (breast cancer) assessment}

In situ or invasive breast cancers in the EPIC-NL study were identified through regular linkages to the Dutch Cancer Registry. Details on the registry linkage have been described elsewhere [26]. Briefly, the Dutch Cancer Registry identifies incident cancer cases by hospital records and is $95 \%$ complete since 1989 .

\section{Characteristics}

At $t 0$, a general questionnaire was filled out by all participants including questions on demographic characteristics, presence of chronic diseases, and risk factors for chronic diseases. Educational level was categorized into low (primary school and lower vocational education) and other (advanced elementary education, intermediate vocational education, higher general secondary education, higher vocational 
education, and university). Diabetes was present if participants were diagnosed with diabetes according to the general questionnaire. Physical activity was assessed by questions on occupational and recreational physical activity during the past year at $t 0$ [29]. The Cambridge Physical Activity Index combined these activities and categorized them into active, moderately active, moderately inactive, and inactive [30, 31]. Smoking behavior was categorized into current, former, or never. Alcohol consumption (gram ethanol per day) was assessed with a validated Food Frequency Questionnaire at t0 [32, 33]. The body mass index was calculated as weight divided by height squared $\left(\mathrm{kg} / \mathrm{m}^{2}\right)$, which were measured during physical examination. At this contact, blood pressure was measured twice in supine position on the left arm using a random zero sphygmomanometer (MORGEN) and on the right arm using a Boso Oscillomat (Prospect), from which the mean was taken. The comparability of both measurement procedures is reported in more detail elsewhere [34]. In MORGEN, serum cholesterol levels were assessed from ethylene-diamine-tetra-acetic acid (EDTA) serum samples drawn during physical examination at $t 0$ using an enzymatic method [26]. In Prospect, cholesterol values are measured with EDTA using serum samples and/or with citrate plasma.

History of CVD before $t 1$ was determined by combining data from the general questionnaire at $t 0$ and data from the Dutch Centre for Health Care Information on hospital discharge diagnosis. The Dutch Centre for Health Care Information holds a standardized computerized register of hospital discharge diagnoses coded according to the International Classification of Diseases, Ninth Revision, Clinical Modification (ICD-9).

\section{Framingham risk score}

The Framingham risk score was calculated for the total study population based on the following characteristics at $t 0$ (median of 8 years before breast cancer diagnosis or reference date): age, smoking behavior (current or past/ never), diabetes (presence or absence), systolic blood pressure $(\mathrm{mmHg})$, total cholesterol $(\mathrm{mmol} / \mathrm{L})$, and high-density lipoprotein (HDL) cholesterol (mmol/L) [24]. The Framingham risk score ranges from -2 to 21 , indicating a 10 -year absolute risk of developing CVD and risk of individual CVD events (hospitalization or death) of less than $1 \%$ to over $30 \%$, respectively. The current study categorized the Framingham risk score into three categories: low (score: $<13$, risk: $<10 \%$ ), intermediate (score: $13-17$, risk: $10-20 \%$ ), high (score: $>17$, risk: $>20 \%$ ).

\section{Outcome assessment}

The outcomes were a CVD event, defined as a hospitalization for CVD or death from CVD, and death from CVD.
Follow-up data on the outcomes were complete until December 31, 2010. Follow-up data on CVD hospitalizations were obtained from the Dutch Centre for Health Care Information. The database was linked to the cohort on the basis of birth date, gender, postal code, and general practitioner with a validated probabilistic method [35]. Causes of death were obtained from the Statistics Netherlands and have been coded according to the Ninth Revision of the International Classification of Diseases (ICD-9) until 1996, and after that, according to the Tenth Revision of the International Statistical Classification of Diseases (ICD-10). Death from CVD was based on primary and secondary causes of death. The primary cause of death is defined as the underlying disease that led to death. The secondary cause of death is either a complication of the primary cause, or another disease which might have contributed to the death.

\section{Data analyses}

Multiple imputation of missing values was performed using 20 imputed datasets to deal with missing values of demographics and cardiovascular risk factors at $t 0$ [36]. In the current study, determinants with missing values were educational level ( $n=16,0.3 \%)$, smoking behavior $(n=4,0.1 \%)$, diabetes $(n=6,0.1 \%)$, systolic blood pressure $(n=21$, $0.4 \%)$, total cholesterol $(n=289,5.3 \%)$, HDL cholesterol ( $n=296,5.5 \%)$, alcohol consumption $(n=16,0.3 \%)$, and body mass index $(n=6,0.1 \%)$.

Means [standard deviation (SD)] and medians [interquartile range (IQR)] were used to describe continuous variables with and without normally distributed data, respectively. Time at risk started at $t 1$ and ended at the date of a CVD event (primary outcome) or date of death from CVD (secondary outcome), death from any other cause, end of study (December 31, 2010), or loss to follow-up $(n=29)$, whichever occurred first. Cox proportional hazard models [37] were used to estimate (adjusted) hazard ratios (HR) and 95\% confidence intervals, comparing women with breast cancer to women without breast cancer. In addition, a competing risk analysis [38] was performed to deal with breast cancer as a competing risk: here the HR estimated by the Fine-Gray model account for the fact that women who died of breast cancer are no longer eligible of experiencing the event of interest.

The analyses on the risk of a CVD event (hospitalization or death due to CVD) were performed for the total study population and stratified by low $(<10 \%)$, intermediate (10-20\%), or high (>20\%) Framingham risk category. The analysis including the total study population was adjusted for Framingham risk score and body mass index. The analysis stratified by Framingham risk category was adjusted for age at $t 1$, i.e., the stratification by Framingham risk created new groups and therefore women within these groups were no 
longer age-matched, and body mass. The analysis on the risk of death from CVD was performed only for the total study population and adjusted for Framingham risk score; the low number of deaths did not allow for stratification by Framingham risk category. In addition, a sensitivity analysis was performed excluding women with a history of CVD to test the hypothesis that women with a known risk of CVD at breast cancer diagnosis receive less cardiac toxic breast cancer treatments.

Statistical analyses were conducted using IBM SPSS statistics version 23, except for the competing risk analyses which were conducted with SAS version 9.4.

\section{Results}

At EPIC-NL cohort enrolment ( $t 0)$, median age of the study population was 54 years (IQR $=50-60)$ for women with breast cancer and women without breast cancer (Table 1). At $t 0$, median Framingham risk score was not different for women who would develop breast cancer $(13, \mathrm{IQR}=9-16)$ than for women who would not develop breast cancer (12, IQR = 9-16) (Table 1). The majority of women with and without breast cancer were in the low Framingham risk category: 61.3 and $66.0 \%$, respectively. The mean body mass index at $t 0$ was comparable for women with and without breast cancer in the low Framingham risk category: 25.2 $(\mathrm{SD}=3.7)$ and $25.1(\mathrm{SD}=3.8)$, respectively (Supplemental material Table A). In the intermediate and high Framingham risk categories, the mean body index was also comparable between women with breast cancer $(27.3(\mathrm{SD}=4.2)$ and 28.5 ( $\mathrm{SD}=3.8)$, respectively) and without breast cancer (27.2 ( $\mathrm{SD}=4.2)$ and $28.1(\mathrm{SD}=4.5)$, respectively).

Breast cancer patients had 5 years (IQR $=2-9$ ) median follow-up (since $t 1$ ) and this was 6 years (IQR $=3-10$ ) for women without breast cancer (Table 1). During this period, 72 women with breast cancer (6.5\%) and 290 without breast cancer (6.7\%) were hospitalized for CVD (Table 2). Hospitalizations for acute pulmonary heart disease and heart failure were more common in women with breast cancer than in women without breast cancer. There were 24 women with breast cancer $(2.2 \%)$ and 57 women without breast cancer (1.3\%) who died of CVD as primary or secondary cause. Coronary heart disease and cerebrovascular accident were the most common causes of death from CVD in both groups. Death from breast cancer was the most prevalent cause of death among women with breast cancer $(n=115,10.4 \%)$.

The risk of a CVD event (hospitalization or death due to CVD) did not differ between women with breast cancer and women without breast cancer: adjusted HR $=1.16$ (95\% CI 0.92-1.47) (Table 3). However, in the low Framingham risk category the risk of a CVD event was higher in women with breast cancer than in women without breast cancer: adjusted
$\mathrm{HR}=1.44$ (95\% CI 1.00-2.06). Excluding women with a history of CVD slightly increased this risk (Supplemental material Table B). Furthermore, in the total study population, the risk of death from CVD was higher in women with breast cancer than in women without breast cancer: adjusted $\mathrm{HR}=1.77$ (95\% CI 1.10-2.86). The competing risk analyses did not change the interpretation of the results described above (Supplemental material Table C).

\section{Discussion}

The results of this study indicate that the risk of a CVD event (hospitalization or death) among women with a low Framingham risk $(<10 \%)$ is $44 \%$ higher in women with breast cancer compared to women without breast cancer. No difference was observed in the total study population. We did find that women with breast cancer have an adjusted 77\% higher risk of death from CVD than women without breast cancer.

Although breast cancer is the main cause of death in women with breast cancer, CVD is increasingly recognized as an important contributor to mortality in breast cancer survivors [39-41]. CVD may be related to cardiac toxic or metabolic effects of some breast cancer treatments such as trastuzumab, anthracycline-based regimens, and radiotherapy $[9,42-44]$.

Several CVD disorders may contribute to a higher CVD risk following breast cancer. Women with breast cancer in the low Framingham risk category were more often hospitalized with heart failure or acute pulmonary heart disease than low-risk women without breast cancer. Heart failure is a known complication induced by anthracycline-based chemotherapies, trastuzumab, and radiotherapy-induced cardiomyopathy due to coronary artery calcifications caused by high radiotherapy heart dose [45-47]. Acute pulmonary heart disease can be caused by vascular changes as a result of tissue damage due to radiotherapy, as part of the lungs is irradiated [48]. Both heart failure and radiation-induced pulmonary damage may become evident during the first year after treatment or later $[48,49]$. We also observed that women with breast cancer died more often due to a cerebrovascular accident. Women who received hormonal treatment (tamoxifen) had a 90\% higher risk of a cerebrovascular accident [50]. Studies reported conflicting results on the association between cerebrovascular accident and radiotherapy to the supraclavicular lymph nodes: Nilsson et al. [51] found a $12 \%$ higher risk for women with a history of breast cancer, while Hooning et al. [21] did not found a higher risk in women with breast cancer [50, 51].

A study that stratified women by CVD risk at breast cancer diagnosis showed that in the low CVD risk group, women treated with radiotherapy were not at increased risk 
Table 1 Characteristics of 1103 women with breast cancer and 4328 matched women without breast cancer at time of original cohort (EPIC-NL) enrolment $(t 0)$ and at time of breast cancer diagnosis or reference $(t 1)$

\begin{tabular}{|c|c|c|}
\hline & $\begin{array}{l}\text { Women with breast } \\
\text { cancer } \\
n=1103\end{array}$ & $\begin{array}{l}\text { Women } \\
\text { without breast } \\
\text { cancer } \\
n=4328\end{array}$ \\
\hline \multicolumn{3}{|l|}{ At time of original cohort enrolment $(t 0)$} \\
\hline \multicolumn{3}{|l|}{ Original cohort, $\%(n)$} \\
\hline Prospect & 70.4 (776) & $68.9(2984)$ \\
\hline MORGEN & $29.6(327)$ & $31.1(1344)$ \\
\hline Age at $t 0$, year, median (IQR) & $54(50-60)$ & $54(50-60)$ \\
\hline Low education, $\%(n)^{\mathrm{a}}$ & $45.2(499)$ & $43.9(1898)$ \\
\hline \multicolumn{3}{|l|}{ Physical activity, \% (n) } \\
\hline Inactive & $8.2(90)$ & $6.2(270)$ \\
\hline Moderately inactive & $26.5(292)$ & $25.0(1080)$ \\
\hline Moderately active & $25.7(284)$ & $27.1(1174)$ \\
\hline Active & $39.6(437)$ & $41.7(1804)$ \\
\hline \multicolumn{3}{|l|}{ Smoking behavior, $\%(n)$} \\
\hline Current & $25.5(281)$ & $24.7(1069)$ \\
\hline Former & $36.2(400)$ & $32.6(1413)$ \\
\hline Never & $38.3(422)$ & $42.7(1846)$ \\
\hline Alcohol consumption, g/day, mean (SD) & $10.3(13.7)$ & $9.1(12.4)$ \\
\hline Diabetes, \% (n) & $2.4(27)$ & $2.0(86)$ \\
\hline Systolic blood pressure, $\mathrm{mmHg}$, mean (SD) & $130.8(20.3)$ & $128.6(20.0)$ \\
\hline Total cholesterol, mmol/L, mean (SD) & $5.9(1.1)$ & $5.9(1.1)$ \\
\hline HDL cholesterol, mmol/L, mean (SD) & $1.5(0.4)$ & $1.5(0.4)$ \\
\hline Body mass index, $\mathrm{kg} / \mathrm{m}^{2}$, mean (SD) & $25.7(4.1)$ & $25.2(4.1)$ \\
\hline Framingham risk score, median (IQR) ${ }^{\mathrm{b}}$ & $13(9-16)$ & $12(9-16)$ \\
\hline \multicolumn{3}{|l|}{ Framingham risk categories, $\%(n)^{\mathrm{b}}$} \\
\hline$<10 \%$ & $61.3(676)$ & $66.0(2856)$ \\
\hline $10-20 \%$ & $29.1(321)$ & $26.1(1131)$ \\
\hline $20 \%$ & $9.6(106)$ & $7.9(341)$ \\
\hline \multicolumn{3}{|l|}{ At time of breast cancer diagnosis or reference $(t 1)$} \\
\hline Age at $\mathrm{t} 1$, year, median (IQR) & $63(56-68)$ & $63(56-68)$ \\
\hline \multicolumn{3}{|l|}{ Calendar year of $\mathrm{t} 1, \mathrm{~A} 2$} \\
\hline 1993-1999 & $26.7(294)$ & $26.6(1153)$ \\
\hline $2000-2005$ & $38.3(422)$ & $38.3(1658)$ \\
\hline $2006-2010$ & $35.1(387)$ & $35.1(1517)$ \\
\hline History of cardiovascular disease at $\mathrm{t} 1, \%(n)$ & $68(6.2)$ & $219(5.1)$ \\
\hline Time between $t 0$ and $\mathrm{t} 1$, year, median (IQR) & $8(4-11)$ & $8(4-11)$ \\
\hline $\begin{array}{l}\text { Follow-up time since t1 (until end of study), year, median } \\
\text { (IQR) }\end{array}$ & $5(2-9)$ & $6(3-10)$ \\
\hline
\end{tabular}

Women were matched by (1) age at original cohort enrolment ( $t 0)$ and (2) time between original cohort enrolment and breast cancer diagnosis $(t 1-t 0)$

$I Q R$ interquartile range, $S D$ standard deviation

${ }^{a}$ Low educational level: lower vocational training or primary school

${ }^{\mathrm{b}}$ Framingham risk score is based on age at original cohort enrolment, smoking behavior, diabetes, systolic blood pressure, and total and HDL cholesterol of CVD [52]. However, CVD risk was increased for women with an intermediate or high CVD risk [52]. These results are, however, difficult to compare with ours as a comparison with women without breast cancer is lacking. Our finding of a higher risk of CVD death in women with breast cancer is in line with many other studies [7, 39, 53, 54]. Riihimaki et al. showed that women with breast cancer have a 1.29 time higher risk of dying of heart failure [53]. They did, however, not correct for CVD risk factors other than age. Bradshaw et al. reported a 1.9 times increased risk of 
Table 2 Cardiovascular disease hospitalization and/or death and other causes of death in 1103 women with breast cancer and 4328 matched women until December 31, 2010

\begin{tabular}{|c|c|c|c|c|}
\hline & ICD-9 & ICD-10 & $\begin{array}{l}\text { Women with } \\
\text { breast cancer [\% } \\
(n)]\end{array}$ & $\begin{array}{l}\text { Women without } \\
\text { breast cancer }[\% \\
(n)]\end{array}$ \\
\hline \multicolumn{3}{|l|}{ Hospitalization for CVD } & $6.5(72)$ & $6.7(290)$ \\
\hline Coronary heart disease & $\begin{array}{l}\text { 410-414, 427.5, 798.1, 798.2, } \\
\quad 798.9\end{array}$ & I20-I25, I46, R96 & $2.5(28)$ & $3.2(137)$ \\
\hline Cerebrovascular accident & $430-434,436$ & I60-I67, I69, G45 & $1.1(12)$ & $2.1(89)$ \\
\hline Acute pulmonary heart disease & 415 & I 27 & $1.3(14)$ & $0.3(12)$ \\
\hline Heart failure & 428 & $\mathrm{I} 50$ & $0.8(9)$ & $0.5(22)$ \\
\hline $\begin{array}{l}\text { Arterial embolism and throm- } \\
\text { bosis }\end{array}$ & 444 & I74 & $0.3(3)$ & $0.3(11)$ \\
\hline Other & $440-443$ & I70-I73 & $0.5(6)$ & $0.4(19)$ \\
\hline \multicolumn{3}{|l|}{ Death from $C D^{a}$} & $2.2(24)$ & $1.3(57)$ \\
\hline Coronary heart disease & $\begin{array}{l}\text { 410-414, 427.5, 798.1, 798.2, } \\
\quad 798.9\end{array}$ & I20-I25, I46, R96 & $0.4(4)$ & $0.5(23)$ \\
\hline Cerebrovascular accident & $430-438$ & I60-I67, I69, G45 & $0.7(8)$ & $0.4(16)$ \\
\hline Other & $\begin{array}{l}401,415,417,424.1,424.2,424.9 \\
425,427.3,427.9,428,440,441 \\
456\end{array}$ & $\begin{array}{l}\mathrm{I} 10, \mathrm{I} 26, \mathrm{I} 27, \mathrm{I} 35, \mathrm{I} 36, \mathrm{I} 38, \mathrm{I} 48, \\
\mathrm{I} 49.9, \mathrm{I} 50, \mathrm{I} 70, \mathrm{I} 71, \mathrm{I} 85\end{array}$ & $1.1(12)$ & $0.4(18)$ \\
\hline \multicolumn{3}{|c|}{ Primary cause of death other than CVD } & $14.6(161)$ & $3.0(170)$ \\
\hline Breast cancer & 174 & $\mathrm{C} 50$ & $10.4(115)$ & $0.0(0)$ \\
\hline Other type of cancer & $140-173,175-232,234-239$ & $\mathrm{C} 00-\mathrm{C} 49, \mathrm{C} 51-\mathrm{C} 97, \mathrm{D} 00-\mathrm{D} 49$ & $2.6(29)$ & $2.3(98)$ \\
\hline Other & All other codes & All other codes & $1.5(17)$ & $1.6(72)$ \\
\hline
\end{tabular}

Numbers may overlap as women with CVD morbidity may have died of CVD ( $n=4$ or $n=22$ for women with or without breast cancer, respectively) or due to another cause

Women were matched by (1) age at original cohort enrolment ( $t 0)$ and (2) time between original cohort enrolment and breast cancer diagnosis $(t 1-t 0)$

$C V D$ cardiovascular disease, $I C D$ international classification of diseases

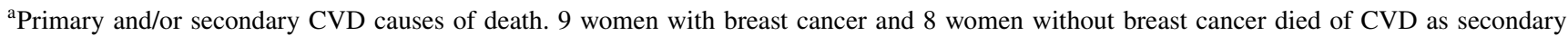
cause of death

CVD death in women with breast cancer, after adjustment for traditional CVD risk factors [7]. This risk manifested approximately 7 years after diagnosis. Furthermore, studies have found increased risk of CVD events up to and beyond 20 years after diagnosis $[8,9,55]$. Age is a well-known CVD risk factor [56] and cardiac toxicity induced by radiotherapy manifest itself many years following treatment $[15,57]$. As the current study has a relative short follow-up time (median of 5-6 years), this may indicate that the risk of death from CVD in breast cancer patients may become larger over time.

There is also a suggestive clarification for the observations in our study. The sensitivity analysis shows that the risk of a CVD event in women with breast cancer with a low Framingham risk score was higher when women with a history of CVD were excluded. This may indicate that in clinical practice women with a higher CVD risk, i.e., history of CVD, receive less cardiac toxic cancer treatments than women without a higher CVD risk [58]. As such, women with breast cancer in the low Framingham risk category may have received more often systemic therapy, i.e., anthracyclines and trastuzumab, and radiotherapy (including differences in laterality of the irradiated breast and targeted volumes) than women with an intermediate or high Framingham risk. Unfortunately, we were not able to test other hypotheses related to breast cancer treatment and characteristics as this information is missing for over one-third of patients.

We were not able to account for changes in CVD risk factors after EPIC enrolment. We assume that these factors used for calculating the Framingham risk score remained more or less similar until time of breast cancer diagnosis $(t 1)$ and thereafter. However, CVD risk factors may have changed between $t 0$ and $t 1$ (median time of 8 years) and after $t 0$. This would result in women shifting to another Framingham risk category. It Is unclear how this would affect our results. Another concern is that we likely have missed women with CVD. The use of hospital discharge registry underestimates the true incidence rates, especially for coronary heart disease and heart failure [59]. This underestimation is most likely nondifferential and 
Table 3 The risk of cardiovascular disease hospitalization and/or death following breast cancer for the total study population and by low, intermediate or high Framingham risk prior to diagnosis until at most December 31, 2010

\begin{tabular}{|c|c|c|c|c|c|c|c|}
\hline & $\begin{array}{l}\text { Num- } \\
\text { ber of } \\
\text { women }\end{array}$ & Total PY & Number of CVD $(\%)^{\mathrm{a}}$ & $\begin{array}{l}\text { Number of } \\
\text { CVD per } 100 \\
\text { PY }\end{array}$ & Unadjusted $\mathrm{HR}^{\mathrm{b}}$ & Adjusted $\mathrm{HR}^{\mathrm{b}, \mathrm{c}}$ & Adjusted $\mathrm{HR}^{\mathrm{b}, \mathrm{d}}$ \\
\hline \multicolumn{8}{|c|}{ CVD event (hospitalization or death) } \\
\hline \multicolumn{8}{|c|}{ Total study population $(n=5431)$} \\
\hline $\begin{array}{l}\text { Women without breast } \\
\text { cancer }\end{array}$ & 4328 & 28,035 & $325(7.5)$ & 1.2 & 1 & 1 & 1 \\
\hline $\begin{array}{l}\text { Women with breast } \\
\text { cancer }\end{array}$ & 1103 & 6401 & $92(8.3)$ & 1.4 & $1.23(0.97-1.55)$ & $1.17(0.92-1.57)$ & $1.16(0.92-1.47)$ \\
\hline \multicolumn{8}{|c|}{ Framingham risk $<10 \%(n=3532)$} \\
\hline $\begin{array}{l}\text { Women without breast } \\
\text { cancer }\end{array}$ & 2856 & 18,518 & $129(4.5)$ & 0.7 & 1 & 1 & 1 \\
\hline $\begin{array}{l}\text { Women with breast } \\
\text { cancer }\end{array}$ & 676 & 3783 & $39(5.8)$ & 1 & $1.45(1.01-2.07)$ & $1.45(1.01-2.08)$ & $1.44(1.00-2.06)$ \\
\hline \multicolumn{8}{|c|}{ Framingham risk $10-20 \%(n=1452)$} \\
\hline $\begin{array}{l}\text { Women without breast } \\
\text { cancer }\end{array}$ & 1131 & 7187 & $124(10.9)$ & 1.7 & 1 & 1 & 1 \\
\hline $\begin{array}{l}\text { Women with breast } \\
\text { cancer }\end{array}$ & 321 & 2031 & $30(9.3)$ & 1.5 & $0.86(0.57-1.29)$ & $0.88(0.59-1.32)$ & $0.88(0.59-1.32)$ \\
\hline \multicolumn{8}{|c|}{ Framingham risk $>20 \%(n=447)$} \\
\hline $\begin{array}{l}\text { Women without breast } \\
\text { cancer }\end{array}$ & 341 & 2287 & 68 (19.9) & 3 & 1 & 1 & 1 \\
\hline $\begin{array}{l}\text { Women with breast } \\
\text { cancer }\end{array}$ & 106 & 584 & $23(21.7)$ & 3.9 & $1.27(0.78-2.07)$ & $1.27(0.78-2.07)$ & $1.27(0.78-2.06)$ \\
\hline \multicolumn{8}{|l|}{ Death from CVD } \\
\hline \multicolumn{8}{|c|}{ Total study population $(n=5431)$} \\
\hline $\begin{array}{l}\text { Women without breast } \\
\text { cancer }\end{array}$ & 4328 & 29,207 & $57(1.3)$ & 0.2 & 1 & 1 & - \\
\hline $\begin{array}{l}\text { Women with breast } \\
\text { cancer }\end{array}$ & 1103 & 6717 & $24(2.2)$ & 0.4 & $1.88(1.16-3.03)$ & $1.77(1.10-2.86)$ & \\
\hline
\end{tabular}

$C V D$ cardiovascular disease, $H R$ hazard ratio, $P Y$ person-years

${ }^{\mathrm{a}}$ Row percentages of number of women

${ }^{\mathrm{b}}$ Cox proportional hazard models

${ }^{c}$ Models including the total study population are adjusted for Framingham risk score and models stratified by Framingham risk category are adjusted for age at breast cancer diagnosis or reference (age at $t 1$ )

${ }^{\mathrm{d}}$ Models including the total study population are adjusted for Framingham risk score and body mass index. Models stratified by Framingham risk category are adjusted for age at breast cancer diagnosis or reference (age at $t 1$ ) and body mass index

therefore not creating bias, as it can be expected that the underestimated incidences are not different for women with breast cancer than for women without breast cancer.

To conclude, this study shows that among women with a low Framingham risk, women with breast cancer have a higher risk of a CVD event (hospitalization or death) than women without breast cancer. Overall, women with breast cancer have a higher risk of death from CVD than women without breast cancer adjusted for Framingham risk score. Future research may investigate an individualized approach for breast cancer patients to optimize the balance between high breast cancer tumor control and minimal cancer treatment-induced CVD risk.

Acknowledgements We thank Statistics Netherlands, the Netherlands Cancer Registry (NKR), and the PHARMO Institute for follow-up data on causes of death, cancer, and cardiovascular disease.

Funding The EPIC-NL study was funded by 'Europe against Cancer' Programme of the European Commission (SANCO); the Dutch Ministry of Public Health, Welfare and Sports (formerly Ministry of Welfare, Public Health and Culture); the Dutch Cancer Society; ZonMW the Netherlands Organization for Health Research and Development; and World Cancer Research Fund (WCRF). The current project was conducted within the framework 'Strategic PhD Partnership Program' 
from the Board of Directors of the University Medical Center Utrecht. The funders had no role in study design, data collection and analysis, decision to publish, or preparation of the manuscript.

\section{Compliance with ethical standards}

Conflict of interest The authors declare that they have no conflict of interest.

Ethics approval and consent to participate The study complies with the Declaration of Helsinki and was approved by the institutional board of the University Medical Center Utrecht (Prospect) and the Medical Ethical Committee of TNO Nutrition and Food Research (MORGEN).

Open Access This article is distributed under the terms of the Creative Commons Attribution 4.0 International License (http://creativeco mmons.org/licenses/by/4.0/), which permits unrestricted use, distribution, and reproduction in any medium, provided you give appropriate credit to the original author(s) and the source, provide a link to the Creative Commons license, and indicate if changes were made.

\section{References}

1. Ferlay J, Soerjomataram I, Ervik M, Dikshit R, Eser S, Mathers C, Rebelo M, Parkin DM, Forman D, Bray F (2014) GLOBOCAN 2012 v1.1, Cancer incidence and mortality worldwide: IARC cancer base. International Journal of Cancer 136(5):359-386

2. Global Burden of Disease Cancer Collaboration, Fitzmaurice C, Allen C et al (2016) Global, regional, and national cancer incidence, mortality, years of life lost, years lived with disability, and disability-adjusted life-years for 32 cancer groups, 1990 to 2015: A systematic analysis for the global burden of disease study. JAMA Oncology 3(4):524-548

3. Myers ER, Moorman P, Gierisch JM et al (2015) Benefits and harms of breast cancer screening: A Systematic review. JAMA 314:1615-1634

4. Berry DA, Cronin KA, Plevritis SK et al (2005) Effect of screening and adjuvant therapy on mortality from breast cancer. New England Journal of Medicine 353:1784-1792

5. Hanrahan EO, Gonzalez-Angulo AM, Giordano SH et al (2007) Overall survival and cause-specific mortality of patients with stage T1a, bN0M0 breast carcinoma. Journal of Clinical Oncology 25:4952-4960

6. Chapman JA, Meng D, Shepherd L et al (2008) Competing causes of death from a randomized trial of extended adjuvant endocrine therapy for breast cancer. Journal of the National Cancer Institute 100:252-260

7. Bradshaw PT, Stevens J, Khankari N et al (2016) Cardiovascular disease mortality among breast cancer survivors. Epidemiology 27:6-13

8. Colzani E, Liljegren A, Johansson AL et al (2011) Prognosis of patients with breast cancer: Causes of death and effects of time since diagnosis, age, and tumor characteristics. Journal of Clinical Oncology 29:4014-4021

9. EBCTCG (Early Breast Cancer Trialists' Collaborative Group), McGale P, Taylor C et al (2014) Effect of radiotherapy after mastectomy and axillary surgery on 10-year recurrence and 20-year breast cancer mortality: Meta-analysis of individual patient data for 8135 women in 22 randomised trials. The Lancet 383:2127-2135

10. McGale P, Darby SC, Hall P et al (2011) Incidence of heart disease in 35,000 women treated with radiotherapy for breast cancer in Denmark and Sweden. Radiotherapy and Oncology 100:167-175

11. Clarke M, Collins R, Darby S et al (2005) Effects of radiotherapy and of differences in the extent of surgery for early breast cancer on local recurrence and 15-year survival: An overview of the randomised trials. The Lancet 366:2087-2106

12. Dalfardi B, Kashy-Zonouzy K, Asvadi-Kermani T (2014) Chemotherapy-induced cardiomyopathy in breast cancer patients. Research in Cardiovascular Medicine 3:e19096

13. Chavez-MacGregor M, Zhang N, Buchholz TA et al (2013) Trastuzumab-related cardiotoxicity among older patients with breast cancer. Journal of Clinical Oncology 31:4222-4228

14. Pinder MC, Duan Z, Goodwin JS et al (2007) Congestive heart failure in older women treated with adjuvant anthracycline chemotherapy for breast cancer. Journal of Clinical Oncology 25:3808-3815

15. Darby SC, Bronnum D, Correa C et al (2010) A dose-response relationship for the incidence of radiation-related heart disease. Journal International Journal of Radiation Oncology Biology Physics 78:S49-S50

16. Rehammar JC, Jensen MB, McGale P et al (2017) Risk of heart disease in relation to radiotherapy and chemotherapy with anthracyclines among 19,464 breast cancer patients in Denmark, 19772005. Radiotherapy and Oncology 123:299-305

17. Smith LA, Cornelius VR, Plummer CJ et al (2010) Cardiotoxicity of anthracycline agents for the treatment of cancer: Systematic review and meta-analysis of randomised controlled trials. BMC Cancer 10:337

18. Moja L, Brambilla C, Compagnoni A et al (2006) Trastuzumab containing regimens for early breast cancer. Cochrane Database System. https://doi.org/10.1002/14651858.CD006243

19. Koene RJ, Prizment AE, Blaes A et al (2016) Shared risk factors in cardiovascular disease and cancer. Circulation 133:1104-1114

20. Jawa Z, Perez RM, Garlie L et al (2016) Risk factors of trastuzumab-induced cardiotoxicity in breast cancer: A meta-analysis. Medicine (Baltimore) 95:e5195

21. Hooning MJ, Botma A, Aleman BM et al (2007) Long-term risk of cardiovascular disease in 10-year survivors of breast cancer. Journal of the National Cancer Institute 99:365-375

22. McCullough ML, Gapstur SM, Shah R et al (2016) Pre- and postdiagnostic diet in relation to mortality among breast cancer survivors in the CPS-II Nutrition Cohort. Cancer Causes and Control 27(11):1303-1314

23. Nichols HB, Trentham-Dietz A, Egan KM et al (2009) Body mass index before and after breast cancer diagnosis: Associations with all-cause, breast cancer, and cardiovascular disease mortality. Cancer Epidemiology Biomarkers Prevention 18:1403-1409

24. D'Agostino RBS, Vasan RS, Pencina MJ et al (2008) General cardiovascular risk profile for use in primary care: The Framingham Heart Study. Circulation 117:743-753

25. Bingham S, Riboli E (2004) Diet and cancer: The European prospective investigation into cancer and nutrition. Nature Reviews Cancer 4:206-215

26. Beulens JW, Monninkhof EM, Verschuren WM et al (2010) Cohort profile: The EPIC-NL study. International Journal of Epidemiology 39:1170-1178

27. Smit HA, Verschuren W, Bueno-de-Mesquita HB (1994) Seidell JC. Doelstellingen en werkwijze, Monitoring van Risicofactoren en Gezondheid in Nederland (MORGEN-project), p 263200001

28. Boker LK, van Noord PA, van der Schouw YT et al (2001) Prospect-EPIC Utrecht: Study design and characteristics of the cohort population. European Prospective Investigation into Cancer and Nutrition. European Journal of Epidemiology 17:1047-1053

29. Haftenberger M, Schuit AJ, Tormo MJ et al (2002) Physical activity of subjects aged 50-64 years involved in the European 
Prospective Investigation into Cancer and Nutrition (EPIC). Public Health Nutr 5:1163-1176

30. Wareham NJ, Jakes RW, Rennie KL et al (2003) Validity and repeatability of a simple index derived from the short physical activity questionnaire used in the European Prospective Investigation into Cancer and Nutrition (EPIC) study. Public Health Nutrition 6:407-413

31. InterAct Consortium, Peters T, Brage S et al (2012) Validity of a short questionnaire to assess physical activity in 10 European countries. European Journal of Epidemiology 27:15-25

32. Ocke MC, Bueno-de-Mesquita HB, Goddijn HE et al (1997) The Dutch EPIC food frequency questionnaire. I. Description of the questionnaire, and relative validity and reproducibility for food groups. International Journal of Epidemiology 26(Suppl 1):S37-S48

33. Ocke MC, Bueno-de-Mesquita HB, Goddijn HE et al (1997) The Dutch EPIC food frequency questionnaire II. Relative validity and reproducibility for nutrients. International Journal of Epidemiology 26(Suppl 1):S49-S58

34. Schulze MB, Kroke A, Saracci R et al (2002) The effect of differences in measurement procedure on the comparability of blood pressure estimates in multi-centre studies. Blood Press Monitoring 7:95-104

35. Herings RM, Bakker A, Stricker BH et al (1992) Pharmaco-morbidity linkage: A feasibility study comparing morbidity in two pharmacy based exposure cohorts. Journal of Epidemiology and Community Health 46:136-140

36. van der Heijden GJ, Donders AR, Stijnen T et al (2006) Imputation of missing values is superior to complete case analysis and the missing-indicator method in multivariable diagnostic research: A clinical example. Journal of Clinical Epidemiology 59:1102-1109

37. Cox DR (1972) Regression models and life-tables. Journal of the Royal Statistical Society 34:187-202

38. Fine JPGR (1999) A proportional hazards model for the subdistribution of a competing risk. Journal of the American Statistical Association 94:496-509

39. Gernaat SAM, Ho PJ, Rijnberg N et al (2017) Risk of death from cardiovascular disease following breast cancer: A systematic review. Breast Cancer Research Treatment 26:S49

40. Hooning MJ, Aleman BM, van Rosmalen AJ et al (2006) Causespecific mortality in long-term survivors of breast cancer: A 25-year follow-up study. International Journal of Radiation Oncology Biology Physics 64:1081-1091

41. Schairer C, Mink PJ, Carroll L et al (2004) Probabilities of death from breast cancer and other causes among female breast cancer patients. Journal of the National Cancer Institute 96:1311-1321

42. Zaorsky NG, Churilla TM, Egleston BL et al (2016) Causes of death among cancer patients. Annals of Oncology 28(2):400-407

43. Doyle JJ, Neugut AI, Jacobson JS et al (2005) Chemotherapy and cardiotoxicity in older breast cancer patients: A population-based study. Journal of Clinical Oncology 23:8597-8605

44. Early Breast Cancer Trialists' Collaborative Group (2005) (EBCTCG). Effects of chemotherapy and hormonal therapy for early breast cancer on recurrence and 15-year survival: An overview of the randomised trials. The Lancet 365:1687-1717

45. Slamon DJ, Leyland-Jones B, Shak S et al (2001) Use of chemotherapy plus a monoclonal antibody against HER2 for metastatic breast cancer that overexpresses HER2. New England Journal of Medicine 344:783-792

46. Vejpongsa P, Yeh ET (2014) Prevention of anthracycline-induced cardiotoxicity: Challenges and opportunities. Journal of the American College of Cardiology 64:938-945

47. Vasu S, Hundley WG (2013) Understanding cardiovascular injury after treatment for cancer: An overview of current uses and future directions of cardiovascular magnetic resonance. Journal of Cardiovascular Magnetic Resonance 15(1):66

48. Omarini C, Thanopoulou E, Johnston SR (2014) Pneumonitis and pulmonary fibrosis associated with breast cancer treatments. Breast Cancer Research Treatment 146:245-258

49. Yeh ET, Bickford CL (2009) Cardiovascular complications of cancer therapy: Incidence, pathogenesis, diagnosis, and management. Journal of the American College of Cardiology 53:2231-2247

50. Hooning MJ, Dorresteijn LD, Aleman BM et al (2006) Decreased risk of stroke among 10-year survivors of breast cancer. Journal of Clinical Oncology 24:5388-5394

51. Nilsson G, Holmberg L, Garmo H et al (2005) Increased incidence of stroke in women with breast cancer. European Journal of cancer 41:423-429

52. Onwudiwe NC, Kwok Y, Onukwugha E et al (2014) Cardiovascular event-free survival after adjuvant radiation therapy in breast cancer patients stratified by cardiovascular risk. Cancer Medicine 3:1342-1352

53. Riihimaki M, Thomsen H, Brandt A et al (2012) Death causes in breast cancer patients. Annals of Oncology 23:604-610

54. Roychoudhuri R, Robinson D, Putcha V et al (2007) Increased cardiovascular mortality more than fifteen years after radiotherapy for breast cancer: A population-based study. BMC Cancer 7:9

55. Darby SC, McGale P, Taylor CW et al (2005) Long-term mortality from heart disease and lung cancer after radiotherapy for early breast cancer: Prospective cohort study of about 300,000 women in US SEER cancer registries. The Lancet Oncology 6:557-565

56. Tsao CW, Vasan RS (2015) Cohort Profile: The Framingham Heart Study (FHS): Overview of milestones in cardiovascular epidemiology. International Journal of Epidemiology 44:1800-1813

57. Cuomo JR, Sharma GK, Conger PD et al (2016) Novel concepts in radiation-induced cardiovascular disease. World Journal of Cardiology 8:504-519

58. Armenian SH, Lacchetti C, Barac A et al (2017) Prevention and monitoring of cardiac dysfunction in survivors of adult cancers: American Society of Clinical Oncology Clinical Practice Guideline. Journal of Clinical Oncology 35:893-911

59. Merry AH, Boer JM, Schouten LJ et al (2009) Validity of coronary heart diseases and heart failure based on hospital discharge and mortality data in the Netherlands using the cardiovascular registry Maastricht cohort study. European Journal of Epidemiology 24:237-247 